\title{
Astronomy in Chile: Assessment of scientific productivity through a bibliometric analysis
}

\author{
Rodrigo Cortes ${ }^{\star}$, Denise Depoortere ${ }^{\star \star}$, and Lucina Malaver ${ }^{\star \star \star}$ \\ Bibliotecas UC, Pontificia Universidad Catolica de Chile
}

\begin{abstract}
The skies of Northern Chile are considered among the best in the world for astronomy due to their geographical, climatic and atmospheric conditions. In fact, during the last several decades, a great number of astronomical observatories have been built by space research institutions devoted to space research, turning Chile into one of the countries with the greatest astronomical observation capacity in the world. Consequently, it is relevant to explore and assess the development of astronomy in Chile during the last ten years (2005-2015), carrying out a bibliometric analysis to extract traditional metrics, complemented with alternative metrics, to identify the Chilean production and scientific contribution of research in this field of knowledge. The results from traditional metrics, based on the information obtained in the Web of Science (WoS) database analyzed through InCites for the Astronomy \& Astrophysics category indicate a sustained increase of the scientific production for the discipline during the last ten years. In particular, the Normalized Citation Impact of organizations and institutions conducting research in Chile is above the worldwide average. On the other hand, the alternative metrics, including for instance, the altmetrics types presented by the SCOPUS database, reflect that the Chilean research impact is much lower in the context of social networks.
\end{abstract}

\section{Introduction}

Chile is quite active in astronomical research given its special sky conditions. The skies of Northern Chile are regarded among the best in the world for astronomy due to their geographical, climatic and atmospheric conditions like the absence of clouds most of the year with 340 clear sky days ${ }^{1}$, dry soils, and low light intensity or pollution. During the last decades, a great number of astronomical observatories have been built by institutions devoted to space research, turning Chile into one of the countries with the greatest astronomical observation capacity in the world. In fact, it is estimated that by $202070 \%$ of all observational activity of the world will be carried out in Chile. Currently, the number is $40 \%^{2}$, allowing a remarkable advance in scientific production in the area of Astronomy ${ }^{3}$.

\footnotetext{
^e-mail: rcortee@uc.cl

$\star \star$ e-mail: ddepoort@uc.cl

$\star \star \star$ e-mail: lmalaver@uc.cl

${ }^{1}$ Educarchile. 2006, http://www.educarchile.cl/ech/pro/app/detalle?id=75547

${ }^{2}$ Treister, E. 2016, http://www.emol.com/noticias/Tecnologia/2016/05/04/797699/Chile-tendra-todos-los-telescopios-masgrandes-del-mundo.html

${ }^{3}$ Espinoza, C. 2016, http://www.latercera.com/noticia/chile-segundo-en-latinoamerica-en-ranking-de-publicaciones-enrevistas-de-excelencia/
} 


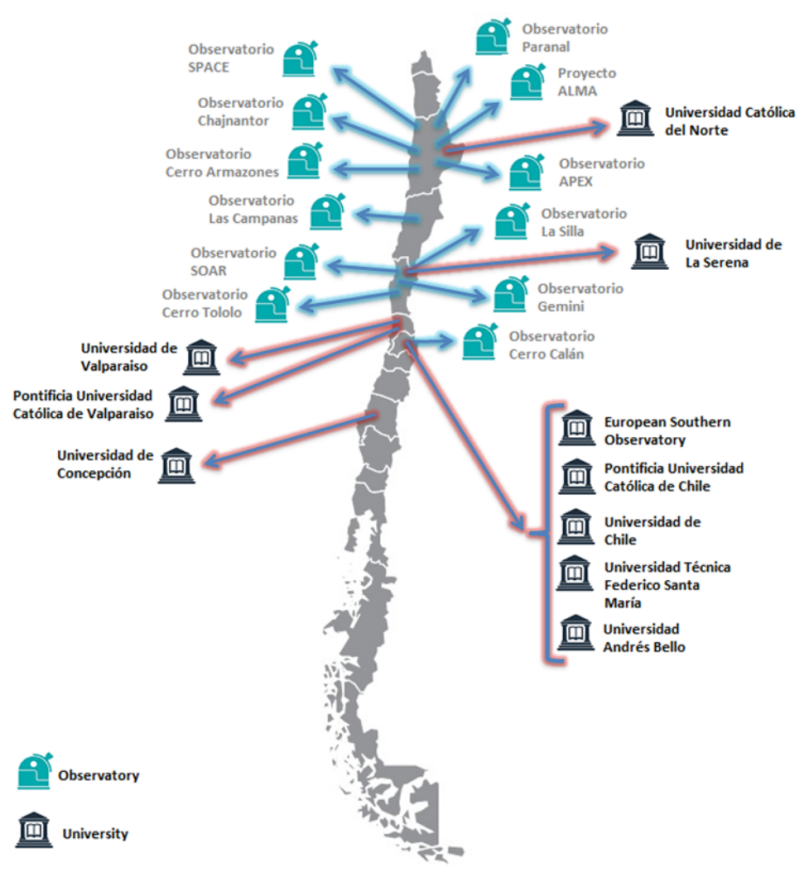

Figure 1. Observatories and Institutions in Chile

Figure 1 displays a map indicating the geographical distribution of observatories and universities related to astronomy in Chile. It can be observed that most of the observatories are located in the North of Chile while the research centers are mostly located in the Central Region.

\section{Objectives}

The main objective of this article consists of showing the important increase of the astronomical scientific productivity developed in Chile during the last decade (2005-2015), analyzed by means of traditional and alternative metrics. Moreover, the specific goals of this work are: (1) To assess the scientific impact of astronomy in Chile; (2) Show the countries and institutions that carry out most of the scientific astronomical collaboration with Chile; and, (3) Investigate the evolution of altmetrics indexes in the Chilean scientific production in Astronomy.

\section{Methodology}

The methodology adopted in this analysis for exploring and assessing the development of astronomy in Chile is based on the study of bibliometric indicators provided by $\mathrm{InCites}^{4}$ and complemented with alternative metrics provided by SCOPUS. The analyzed data correspond to scientific publications of Chile in Astronomy \& Astrophysics over a 10 years span. The first focus of this bibliometric analysis is on the Chilean scientific productivity, identified through the analysis of the authors' institutional

\footnotetext{
${ }^{4}$ InCites is a research analytics tool that allows to analyze institutional productivity and benchmark output against peers worldwide (http://researchanalytics.thomsonreuters.com/m/pdfs/indicators-handbook.pdf)
} 
affiliation. For visualizing research trends and growth of knowledge in this scientific field it is important to identify these scientific publications. The second focus of this bibliometric study is the impact of the published scientific papers, identifying the impact of Chilean scientific production analyzing the times a paper has been cited. The citation of these scientific documents was analyzed based on Normalized Citation Impact (NCI), this measure is used to assess the overall impact of the scientific publications in the category. This type of analysis allows for exploring the scientific context of the field and helps to select meaningful metrics for developing bibliometric methods in local applications.

\section{Results and analysis}

\subsection{Traditional metrics}

This bibliometric analysis focuses on productivity, impact and international collaboration of Chile in Astronomy \& Astrophysics, analyzing a global perspective and their influence throughout the period under study. Quantity and performance indicators were used, such as: number of publications, number of citations and field normalized citation score (Rehn, Gornitzki, Larsson, \& Wadskog 2014).

\begin{tabular}{|c|c|c|c|c|c|}
\hline Year & $\begin{array}{c}\text { Web of } \\
\text { Science } \\
\text { Documents }\end{array}$ & $\begin{array}{c}\text { Productivity } \\
\text { rate }\end{array}$ & Times Cited & $\%$ Docs Cited & $\begin{array}{l}\text { Normalized } \\
\text { Citation } \\
\text { Impact }\end{array}$ \\
\hline 2005 & 440 & - & 14.632 & 93,18 & 1,24 \\
\hline 2006 & 547 & ป 1,24 & 20.550 & 91,77 & 1,31 \\
\hline 2007 & 522 & \& 0,95 & 23.006 & 91,95 & 1,42 \\
\hline 2008 & 592 & † 1,13 & 16.434 & 84,97 & 1,30 \\
\hline 2009 & 605 & 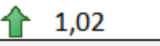 & 21.347 & 85,95 & 1,48 \\
\hline 2010 & 699 & 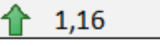 & 18.033 & 84,84 & 1,26 \\
\hline 2011 & 784 & ㄴ 1,12 & 22.795 & 91,96 & 1,58 \\
\hline 2012 & 926 & \} 1,18 & 24.510 & 89,31 & 1,71 \\
\hline 2013 & 880 & Љ 0,95 & 17.666 & 95,23 & 1,55 \\
\hline 2014 & 1.152 & 1 1,31 & 21.698 & 90,19 & 2,20 \\
\hline 2015 & 1.172 & ป 1,02 & 8.663 & 83,79 & 1,40 \\
\hline
\end{tabular}

Figure 2. Annual Evolution of Chilean Scientific Production and Impact Indicators

Figure 2 exhibits the data of the Astronomy \& Astrophysics annual evolution of Chilean scientific production and impact indicators. In the period under study, the Chilean papers annual productivity has tripled. It stands out the year 2014 where it is exceeded in $30 \%$ the productivity with respect to the previous years. In addition, it has a strong impact indicator (NCI) that is above the world average. Therefore, Chile has a high performance within the range of impact of the world scientific community (Greco, Bornmann and Marx 2012).

Figure 3 displays the evolution of papers published annually in this field and the most productive scientific institutions during the last ten years. The European Southern Observatory is the reference for productivity in this area ${ }^{5}$. Pontificia Universidad Catolica de Chile, University of Chile and University of Concepcion are the most productive institutions in this area. This is consistent with the

\footnotetext{
${ }^{5}$ European Southern Observatory. 2017, http://www.eso.org/public/chile/announcements/ann16019/
} 


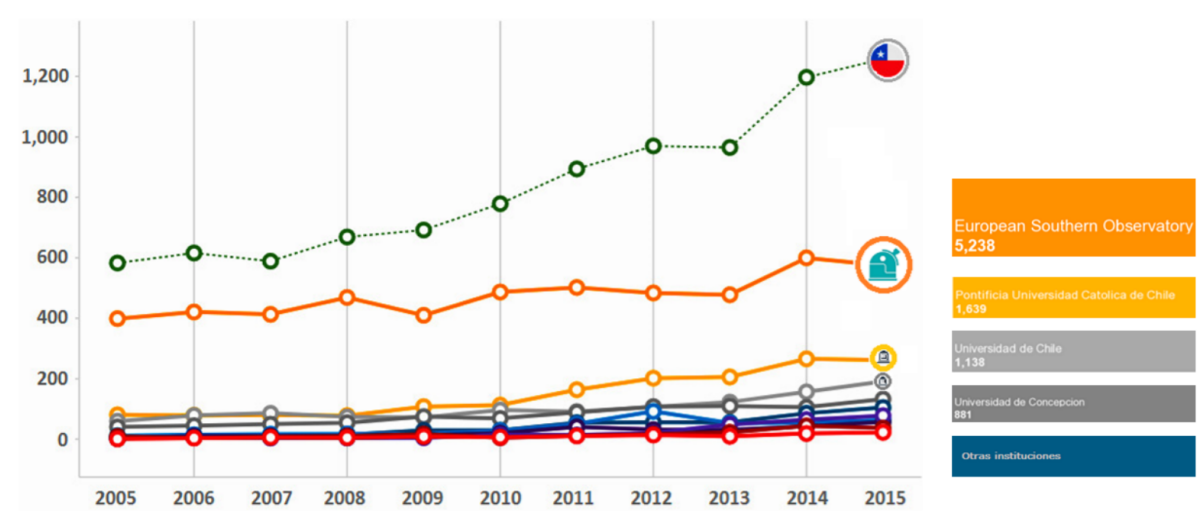

Figure 3. Evolution of Papers Published Annually in Astronomy \& Astrophysics

overall results of the national scientific production (Navarrete 2015). The bibliometric analysis shows that Chilean scientific publications exhibits a positive growth that demonstrates the development of academic research in this area.

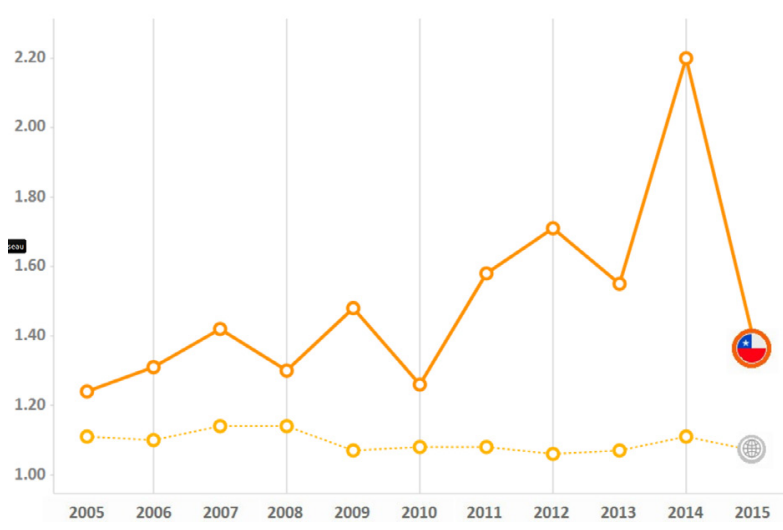

Figure 4. Normalized Citation Impact (NCI)

Figure 4 shows the evolution of Chilean scientific documents citation, analyzed using the Normalized Citation Impact (NCI) in astronomy and astrophysics. Based on these data, the plot indicates that over the last ten years, the Normalized Citation Impact of Chilean scientific documents is higher than the worldwide impact in this field. The figure shows that Chilean papers citation impact in astronomy and astrophysics has been above $20 \%$ of the worldwide impact average, during the period studied. The peak is produced by articles with an unusual high impact for that year.

Figure 5 displays the impact of Chilean top institutions publishing scientific documents in astronomy and astrophysics based on the NCI. Most of the institutions conducting research in Chile in this field are above the worldwide average. On the other hand, for exploring Chilean international collaboration by country, this bibliometric analysis focuses on document counting. 


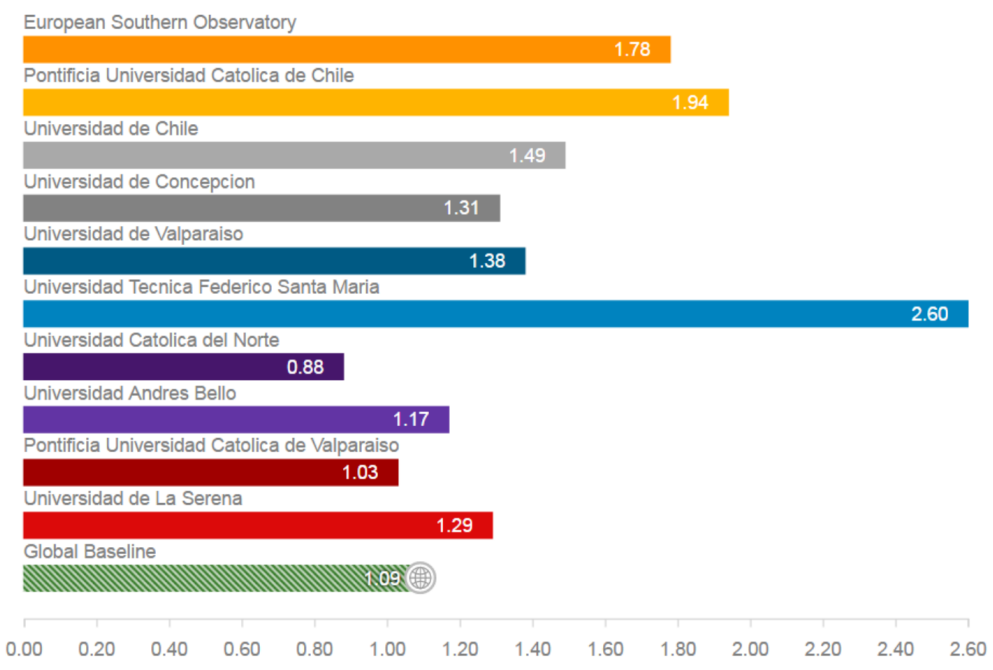

Figure 5. Normalized Citation Impact of Chilean Top Institutions

\begin{tabular}{|c|l|c|c|c|c|c|}
\hline Ranking & Country & $\begin{array}{c}\text { Web of } \\
\text { Science } \\
\text { Documents }\end{array}$ & $\begin{array}{c}\text { Collaboration } \\
\text { WoS } \\
\text { Documents } \\
\text { with Chile }\end{array}$ & Times Cited & $\begin{array}{c}\% \\
\text { Documents } \\
\text { Cited }\end{array}$ & $\begin{array}{c}\text { Normalized } \\
\text { Citation } \\
\text { Impact }\end{array}$ \\
\hline 1 & USA & 4.193 & 50,40 & 151.155 & 94,40 & 2,15 \\
\hline 2 & GERMANY & 2.877 & 34,58 & 103.139 & 94,23 & 2,26 \\
\hline 3 & ENGLAND & 2.249 & 27,03 & 89.699 & 96,40 & 2,60 \\
\hline 4 & FRANCE & 2.134 & 25,65 & 79.654 & 94,05 & 2,48 \\
\hline 5 & ITALY & 1.786 & 21,47 & 67.543 & 95,52 & 2,57 \\
\hline 6 & SPAIN & 1.657 & 19,92 & 64.739 & 95,17 & 2,68 \\
\hline 7 & CANADA & 1.187 & 14,27 & 61.560 & 94,78 & 3,32 \\
\hline 8 & NETHERLANDS & 1.075 & 12,92 & 52.519 & 97,49 & 3,34 \\
\hline 9 & AUSTRALIA & 1.057 & 12,71 & 45.277 & 97,45 & 2,70 \\
\hline 10 & JAPAN & 867 & 10,42 & 35.882 & 93,54 & 2,76 \\
\hline
\end{tabular}

Figure 6. International Collaboration of Chilean Institutions

Figure 6 presents the data of the astronomy and astrophysics international collaboration network of the scientific production between authors of Chilean institutions and other countries (2005-2015). In this case, we show the top 10 countries that have contributed significantly to develop production and impact in the area.

Figure 7 shows the international collaboration network of the scientific production among authors of Chilean institutions and other countries. The US has collaborated with Chile with more than 4,000 documents in the period studied. For another perspective Germany, England and France have more 2,000 documents each in collaboration with Chile in the same period. 


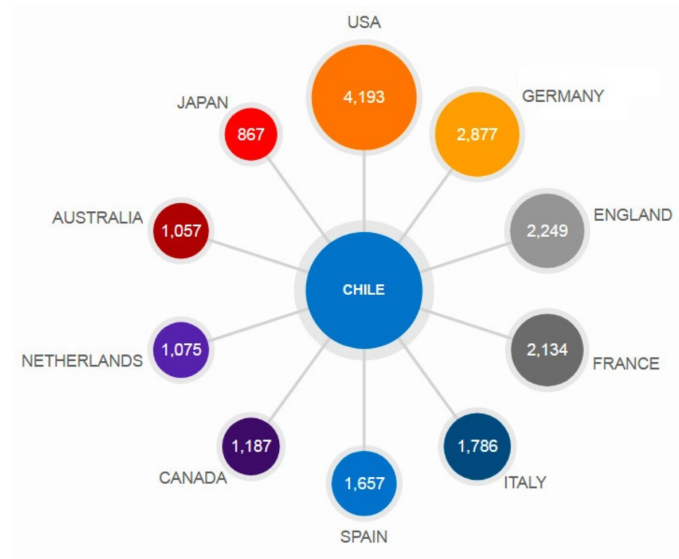

Figure 7. International Collaboration Network

\subsection{Alternative metrics}

The methodological approach of this study is complementing the traditional metrics with the alternative ones. In this case, the Altmetric tool was used to provide information on the dissemination and discussion of research results, as well as a view of the references in non-conventional sources that complement traditional quotations (Melero 2015).

\begin{tabular}{|c|c|c|c|c|c|c|c|c|c|c|c|c|}
\cline { 4 - 13 } & \multicolumn{2}{c|}{ Scholarly Activity } & \multicolumn{3}{|c|}{ Scholar Commentary } & \multicolumn{3}{|c|}{ Social Activity } & Mass Media \\
\hline $\begin{array}{c}\text { Top } \\
\text { articles }\end{array}$ & $\begin{array}{c}\text { Publication } \\
\text { Date }\end{array}$ & $\begin{array}{c}\text { Times } \\
\text { Cited }\end{array}$ & Mendeley & CiteULike & Blogs & Wikipedia & Q \& A sites & Twitter & Facebook & Google+ & Reddit & Noticias \\
\hline 1 & 2007 & 4201 & 225 & 11 & 1 & 7 & 0 & 2 & 1 & 0 & 0 & 0 \\
\hline 2 & 2012 & 3824 & 52 & 5 & 38 & 5 & 3 & 1413 & 29 & 13 & 3 & 13 \\
\hline 3 & 2014 & 3690 & 500 & 1 & 21 & 8 & 1 & 41 & 4 & 4 & 0 & 6 \\
\hline 4 & 2009 & 2470 & 0 & 0 & 1 & 1 & 0 & 3 & 0 & 0 & 0 & 0 \\
\hline 5 & 2006 & 1654 & 60 & 4 & 0 & 1 & 0 & 1 & 0 & 0 & 0 & 0 \\
\hline 6 & 2014 & 1126 & 166 & 0 & 14 & 1 & 2 & 12 & 1 & 2 & 0 & 3 \\
\hline 7 & 2008 & 990 & 28 & 0 & 0 & 1 & 0 & 0 & 0 & 0 & 0 & 0 \\
\hline 8 & 2008 & 848 & 120 & 7 & 1 & 2 & 2 & 0 & 0 & 0 & 0 & 2 \\
\hline 9 & 2014 & 704 & 0 & 0 & 10 & 8 & 1 & 35 & 10 & 3 & 0 & 0 \\
\hline 10 & 2012 & 628 & 105 & 0 & 0 & 0 & 0 & 1 & 0 & 0 & 0 & 0 \\
\hline
\end{tabular}

Figure 8. Top Ten Cited Papers in WoS versus Alternative Metrics through SCOPUS

Figure 8 displays the data of the top ten cited papers in Web of Science that were analyzed in SCOPUS, focusing on alternative metrics in these four aspects: Scholarly Activity, Scholarly Commentary, Mass Media and Social Activity. It can be observed that the use of Mendeley, Blogs and Twitter are important tools to enhance scientific publications. When comparing traditional metrics with alternative metrics, as shown in Figure 9, the Altmetric indicators presented by SCOPUS reflect that the impact of Chilean research in Astronomy \& Astrophysics is low in the context of social networks in the studied period.

\section{Conclusions}

The analysis of traditional metrics from the information obtained in Web of Science analyzed through InCites indicates a steady increase of the scientific production in Astronomy \& Astrophysics during 


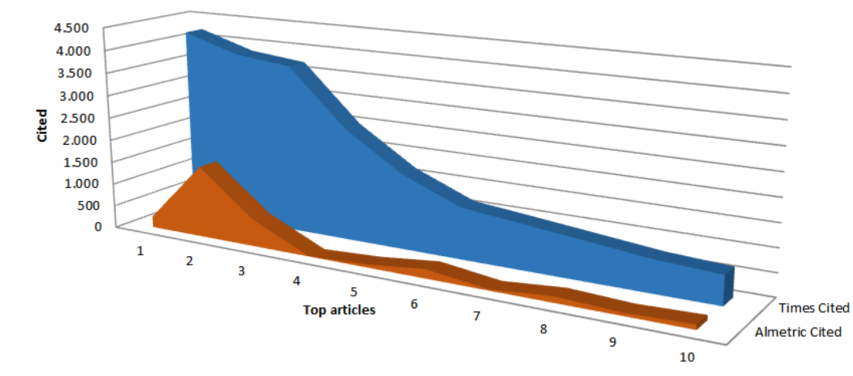

\begin{tabular}{|l|c|c|c|c|c|c|c|c|c|c|}
\cline { 2 - 11 } \multicolumn{1}{c|}{} & 1 & 2 & 3 & 4 & 5 & 6 & 7 & 8 & 9 & 10 \\
\hline $\mathbf{m}$ - Almetric Cited & 247 & 1.574 & 586 & 5 & 66 & 201 & 29 & 134 & 67 & 106 \\
\hline $\mathbf{\square}$ Times Cited & 4.201 & 3.824 & 3.690 & 2.470 & 1.654 & 1.126 & 990 & 848 & 704 & 628 \\
\hline
\end{tabular}

Figure 9. Traditional Metrics versus Alternative Metrics

the last 10 years. In addition, the Normalized Citation Impact of the organizations and institutions that carry out research in Chile is above the average at a worldwide level. Furthermore, alternative metrics presented by SCOPUS show that the impact of the research is low in the context of social networks.

\section{Acknowledgements}

The authors would like to thank the Pontificia Universidad Catolica de Chile for supporting the development of this work and the attendance at the LISA conference. We are also very grateful to the Friends of LISA for travel and registration funding. In addition, we would like to thank the Librarian Patricio Cortes for his fundamental collaboration in this study and to Prof. Wilfredo Palma for his help with the manuscript edition.

\section{References}

[1] A. Greco, L. Bornmann, W. Marx, El profesional de la informacion 21, 607-612 (2012)

[2] R. Melero, Biochemia Medica 25, 152-160 (2015), http://dx.doi.org/10.11613/BM.2015.016

[3] J. Navarrete, Plataforma Cientifica, (2015), http://www.plataformacientifica.cl/que-dicen-losindicadores-sobre-la-produccion-cientifica-en-chile/

[4] C. Rehn, C. Gornitzki, A. Larsson, D. Wadskog, Bibliometric handbook for Karolinska Institutet (Thomson Reuters, USA, 2014), https://kib.ki.se/sites/default/files/bibliometric_handbook_2014.pdf 
